\title{
RECONOCIMIENTO O NEGACIÓN POR LOS ESPANTOLES DEL SIGLO XVI DE UN SISTEMA DE ESCRITURA INDIGENA EN EL MÉXICO CENTRAL
}

\author{
Anne-Marie Wohrer \\ C.I.E.E.I.T. París. Francia.
}

\section{LOS PRIMEROS CONTACTOS.}

Estos contactos se establecieron cuando tuvieron lugar los encuentros de los conquistadores con los mensajeros de Motecubzoma Xocoyotzin y/o de otros señoríos. Los Indios comunican con ellos por medio de "pinturas", la "pintura" (o dibujo) sustituyéndose a la expresión verbal en la ausencia de intérprete o completando en presencia de un intérprete.

Estos contactos se establecen muy temprano: en Julio de 1519, en su primera carta de relación a Carlos Quinto, Hernán Cortés menciona la presencia de dos "libros" en la larga lista de objetos de valor mandados a la corte de España'. En la segunda carta, fechada en $1520^{\circ}$, y la quinta en 1526 , Cortés da parte al emperador de la existencia de verdaderos mapas geográficos dibujados por los indios sobre papel hecho con la corteza de un árbol llamado amacuabuitl ${ }^{3}$ o sobre lienzos de algodón. La precisión de algunos de estos mapas es tal que hubieran podido ser utilizados por un estado mayor. No sólo Cortés los utilizará para la exploración y conquista del territorio de lo que será la Nueva-España ${ }^{4}$ (en la costa del Yucatán, entre otros ejemplos) sino también para enfrentarse con sus enemigos, indígenas o españoles. Es gracias a la representación ejecutada sobre un lienzo por los pintores de Motecubzoma Xocoyotzin que Cortés tuvo noticia de la llegada de la armada de su gran enemigo Diego Velázquez en el puerto de Vera Cruz 5 . 
Bernal Díaz del Castillo ${ }^{6}$ da parte también de la presencia de "libros" y del uso que hacían de lo "escrito" los indígenas para consignar sus cuentas y su historia. Menciona en Tenochtitlan un edificio que podríamos calificar de biblioteca, que como en el de Texcoco, contenía los archivos reales.

Acabada la conquista, instaladas las administraciones civiles o religiosas de la primera Audiencia primero y del virreinato después, los documentos indígenas circulan y suscitan reacciones diversas de parte de los Españoles que los designan bajo el nombre genérico de "pinturas". Expondremos en seguida estas reacciones así como el nivel de conocimiento de estos documentos hacia finales del siglo XVI y principios del XVII.

\section{EL FERVOR ICONOCLASTA.}

Los Españoles, civiles (historiadores de la Conquista, autores de las Relaciones Geográficas) o religiosos, con la ayuda de los descendientes de la nobleza indígena que simpatizaba con ellos y la de los letrados que habían sobrevivido al drama de la Conquista, se dan cuenta de la importancia de las "pinturas" dentro de la sociedad indígena. Sus reacciones van de la condenación-destrucción a la conservación de estos documentos.

La primera reacción, debida a la ignorancia, incomprensión y celo religioso del primer obispo de México, Fr. Juan de Zumárraga ${ }^{7}$ y de sus compañeros o, más adelante, la reacción de Fr. Diego de Landa (franciscano también) en Yucatan, es una "mise à l'Index" de los libros. Están apartados y sometidos a un examen riguroso de parte de las autoridades eclesiásticas y luego clasificados en "reprobados" y "no reprobados". Los "reprobados" son los que tratan de religión, de interpretación de sueño y de astrología. Los segundos, los "no reprobados" son los calendarios y los anales... pero grosso modo, si surge la menor duda, se quema: "... lo que es ceremoniático o sospechoso, lo quemamos.." " escribía un anónimo franciscano entre 1530 y 1534. Los libros pertenecen de facto, en particular durante el gobierno de la primera (1528-1530) y de la segunda audiencia (1531-1535), casi todos a la categoría de los "reprobados" ", es decir a la categoría de los tratados de idolatría, destinados a ser destruidos por el fuego ${ }^{10}$.

Es la suerte que corren numerosos documentos entre los cuales figuraban los archivos de Tenochtitlan y los de Maní en Yucatan, que serán quemados más adelante. La biblioteca de Texcoco, muy a menudo comparada con la de Alejandría por sus riquezas, había sido quemada en 1520: los 
Tlaxcaltecas enemigos de este señorío y aliados de los españoles habían aprovechado el saqueo de esta ciudad para destruirla ${ }^{11}$.

Tanto estos autos de fe como la destrucción de los edificios religiosos fueron desgarradores para los indígenas; un siglo más tarde todavía se quejarán de haber sido despojados de su memoria escrita y de este hecho de gran parte de su pasado. La destrucción fue tal que a fines del siglo XVI según Juan Batista Pomar ${ }^{12}$, casi no quedan pinturas ni "letrados" capaces de interpretarlas; han muerto y sus descendientes ya no saben hacerlo. Cuando, después de haber juntado en el área de Texcoco los pocos documentos que habían subsistido, para reconstituir la historia de sus antepasados, Ixtlilxochitl busca a gente docta para leerlos, no encuentra sino a dos en un reino que, en tiempos precortesianos fue el más "ilustrado" del México Central.

El terror provocado por estos autos de fe acosó algunos poseedores de "pinturas" a quemarlas ${ }^{13}$ para librarse de las persecuciones. Tener un "libro" en su casa estaba considerado como delito, o un cargo más contra el acusado, como sucedió en el juicio del Cacique de Texcoco en $1539^{14}$. Podía ocurrir también que les poseedores de libros fuesen denunciados por indígenas recientemente convertidos ${ }^{15}$.

Por otra parte, el terror indujo otros propietarios a encubrir definitivamente a la vista de los Españoles las "pinturas", escondiéndolas en lugares secretos ${ }^{16}$. Todavía hoy en día surgen de vez en cuando algunos Códices escondidos desde el siglo XVI: conocemos ejemplos en áreas tan distantes geográficamente y culturalmente como la de Tlapa Guerrero con los Lienzos de Chiepetlan y de la Huasteca veracruzana con el Codex de Cuaxicala. Estos manuscritos siguen siendo objetos de una verdadera veneración, recuerdo quizás del carácter divino que poseían algunos de ellos, por lo menos hasta fines del siglo XVI ${ }^{17}$, como el designado por Ixtlilxochit ${ }^{18}$ bajo el nombre de Teoamoxtli y traducido por "diversas cosas de dios y libro divino".

\section{LOS INTENTOS DE ENTENDIMIENTO.}

Así podríamos calificar el segundo tipo de reacción profundamente tachado de arrepentimiento por los excesos cometidos por los primeros religiosos.

Numerosos son los civiles o religiosos que se dan cuenta como Fray Diego Durán cuando escribe "todo lo tenían escrito y pintado en libros y largos papeles..." 19 del uso que habían tenido y podían seguir teniendo las "pinturas" en la nueva sociedad que estaban fundando. 
Fr. Andrés de Olmos desde tan temprano como el año de $1533^{20} \mathrm{y}$ después muchos otros religiosos: Motolinía, Sahagún, Durán, Acosta, Tovar, Mendieta, Torquemada, así como algunos civiles, autores de las Relaciones Geográficas hacia fines del siglo XVI, buscan, juntan y consultan las "pinturas" procedentes de los antiguos y numerosos reinos aliados o enemigos de Tenochtitlan ${ }^{21}$, con el propósito de conocer al pasado indígena.

Los civiles utilizan los conocimientos para "mejor administrar la colonia", los religiosos lo hacen para combatir mejor la idolatría y cristianizar lo más antes a los indígenas. El padre Sahagún lo expresa claramente en el prólogo del Codex Florentino: "El médico no puede acertadamente aplicar las medicinas al enfermo que primero conozca de que tumor o de que causa procede la enfermedad. De manera que el buen médico sea docto en el conocimiento de las medicinas y en el de las enfermedades para aplicar conveniblemente a cada enfermedad la medicina contraria. Los predicadores y confesores, médicos son de las ánimas para curar las enfermedades espirituales - conviene tengan espiritia de las medicinas y de las enfermedades espirituales...".

Presentaremos en seguida el nivel de los conocimientos sobre el aspecto formal, la hechura, el contenido, el oficio de pintor, la enseñanza, y el uso de las "pinturas" en el siglo XVI y principio del XVII.

Las "pinturas" pueden ser objetos muebles o inmuebles. Los primeros son grandes rectángulos llamados "lienzos" o "paños"; paneles de tamaño pequeño que se enrollan: los "rollos"; hojas encuadernadas o dobladas en "biombos". Los objetos inmuebles son paredes pintadas.

Los soportes de las pinturas para los objetos muebles son en tela de fibras de algodón (ichcatl), en papel hecho con fibras de ágave (metl) o con la corteza llamada amatl del árbol amacuabuith en piel de venado. Los soportes, generalmente cubiertos de una capa delgada de estuco ${ }^{22}$, tienen a menudo las dos caras pintadas. La hoja, es decir el "folio" de papel metl es dos veces más grande que el folio europeo. Viene en mayor parte de Tlaxcala. Las "pinturas" aparecen también sobre madera o sobre piedra ${ }^{23}$. El papel de amath, según Díaz del Castillo ${ }^{24}$, era un producto bastante difundido en el mercado de Tenochtitlan. A fines del siglo XVI, se utiliza comúnmente al papel europeo.

Los dibujos están primero delineados por medio de "tinta" o de carbón, y luego coloreados. Estaban probablemente enseñados con una varilla del mismo modo como lo harán más adelante los indígenas al enseñar sus pecados dibujados sobre lienzos ${ }^{25}$ a los religiosos.

Había pintores, por lo menos en las ciudades más importantes del México Central tales como Tenochtitlan, Mixquic, Cuitláhuac, Xochimilco, 
Malinalco, Cuauhnahuac ${ }^{26} . .$. , que trabajaban sin parar. Se llamaban Tlacuilo (esto en el texto nahuatl del Codex Florentino) y más comúnmente amantecatl $^{27}$, término que significa más bien artesano. El oficio de pintor era una especie de cargo que se trasmitía de padre a hijo ${ }^{28}$. Había pintores de corte y también, según Ixtlilxochitl ${ }^{29}$, pintores para cada una de las cinco categorías de libros: libros de anales - de genealogías - de catastro - de ritos y ceremonias - libros de ciencia y de canto. Habla escribas en todas las cortes de justicia ${ }^{30}$.

Según Fr. Toribio de Motolinía ${ }^{31}$, la interpretación de los manuscritos, tratándose sobre todo de los relativos a los agüeros y sueños estaba en cargo de un maestro especializado. De acuerdo con Torquemada ${ }^{32}$, sólo los sacerdotes - llamados por el "rabinos" - y los pintores entendían a las "pinturas".

Fr. Diego Durán ${ }^{33}$ relata que antes de la Conquista, se enseñaba los "Artes" - es decir la ley y la doctrina, la mecánica, astrología, escultura, pintura, guerra - a los hijos de la nobleza en los libros de "pinturas". Landa confirma este hecho en Yucatan ${ }^{34}$. El lema a menudo repetido en las Relaciones Geográficas y en Ixtlilxochitl ${ }^{35}$ "...como parece por pinturas antiguas que les dejaron sus pasados" nos lleva a pensar que las "pinturas" se heredaban.

En la época en que redactó su historia 1560-1580, Durán relata que la lectura de las "pinturas" estaba enseñada a los niños, hecho en contradicción con lo que expresan Pomar y más adelante Ixtlilxochitl ${ }^{36}$.

\section{¿RECONOCIERON LOS ESPANOLES LA EXISTENCIA DE UN SISTEMA INDIGENA DE ESCRITURA?}

Según ellos la escritura no es sino compuesta de caracteres latinos, griegos o hebraicos - quizás cirílicos aunque no esté mencionado el hecho en ninguna parte. Los ideogramas chinos o japoneses, les jeroglíficos egipcios no están considerados como escritura ${ }^{37}$.

En la Nueva-España no hay sino "pinturas", "figuras", "caracteres" (de acuerdo con Cortés, Fr. Gregorio García ${ }^{38}$, Durán, Ixtlilxochitl), "jeroglíficos" ${ }^{39}$ (Acosta, Gregorio García), "signos" (Durán, Mendieta ${ }^{40}$ ), "señales" (Mendieta ${ }^{41}$ ), "efigies" (Durán ${ }^{42}$ ), "imágenes" (Greg. García ${ }^{43}$ ); "cifras" (Durán ${ }^{44}$ ) y a veces "letras" (Durán, I, 228; Torquemada, II, 314) aunque este nombre no corresponda en el contexto de Durán sino al concepto de "pinturas". Según la aplastadora mayoría de los letrados españoles o europeos del siglo XVI y principios del XVII, la escritura no existía en el Nuevo Mundo por el simple hecho de que no estaba compuesta de letras. 
Sin embargo, durante este período de etnocentrismo, los religiosos españoles convencidos de que los indios descendían de los Judíos (que llaman también Fenicios) o de los Cartagineses ${ }^{45}$ (Torquemada lo toma de Aristóteles), o que de todos modos no podían traer su origen sino del Viejo Mundo, se empeñan a buscar pruebas de esta ascendencia. Piensan encontrarlas en la religión indígena que interpretan de tal modo que encuentran concordancias con el mundo judeo-cristiano: el diluvio ${ }^{46}$ corresponde al diluvio en que terminó el Cuarto Sol nabui atl - la espera del Mesías ${ }^{47}$ al retorno de Quetzalcoatl - la virginidad de la madre del Cristo ${ }^{48}$ corresponde a la de la diosa Coatlicue que da luz sin intervención "masculina" a Huitzilopochtli ... y muchos ejemplos más. Pero a pesar de sus esfuerzos, los Españoles no encuentran ninguna huella de la escritura que hubieran debido traer los Judíos en la Nueva-España.

Sólo Fr. D. Durán ${ }^{49}$ et Fr. J. de Mendieta ${ }^{50}$ creen, y hablaremos de esto más adelante, a la presencia antes de la llegada de los Españoles de libros que tenían que ver con la fe christiana, libros que desafortunadamente ellos mismos no han podido ver.

A pesar suyo, numerosos religiosos, al describir el sistema de representaciones de las "pinturas" y su uso bastante común, aislaron componentes de lo que podríamos considerar como un sistema de escritura. Presentaremos sus reflexiones en el orden cronológico.

Según Fr. T. de Motolinía que escribía entre 1536-1542 51 , los indios aunque no tengan letras, tienen "caracteres" y "figuras" que agrupan en forma de libros... los leen y los entienden: es "su escritura". Motolinía añade que estas "figuras" que usan mucho son inteligibles para los indios y que nosotros mismos podemos aprender a entenderlas y que se parecen a la escritura egipcia. Las "pinturas" están bien hechas, los libros merecen ser mirados.

Según Francisco López de Gómara ${ }^{52}$, que publica su obra en 1552, no hay "letras" en las Indias Occidentales sino y sólo en la Nueva-España algunas "figuras" que sirven de "letras" con las cuales los indios anotan y entienden todo y conservan la memoria y su historia. Este modo de escritura se parece a la que tenían los antiguos Egipcios.

Según Fr. Bernardino de Sahagún ${ }^{53}$ los indígenas no tenían ni letras ni caracteres, no sabían escribir. Comunicaban entre ellos por medio de figuras y imágenes de tal modo que conocían y guardaban en memoria todas las cosas que sus antepasados habían hecho, por lo menos mil años antes de la llegada de los Españoles.

Fray Diego Durán se empeña en su Historia redactada entre 15761578 de encontrar en el pasado mítico de la época tolteca no solamente simi- 
litudes entre la religión instaurada por Topiltzin y la religión judeo-cristiana, sino también un origen judeo-cristiano en estos tiempos tan remotos: según él ${ }^{54}$, los indios serían parte de las diez tribus de Israel. Durán encuentra una analogía entre Topiltzin y Santo Tomás o Moisés: camina sobre el agua, es lapidario y hace milagros. Topiltzin hubiera venido en la Nueva-España, hubiera formado discípulos: les sabios "toltecas". Luego, decepcionado, persecutado por Tezcatlipoca y sus acólitos, se hubiera ido por el mar con sus compañeros, después de haber anunciado que dentro de 465 generaciones, unos extranjeros llegarían del oriente y castigarían a los que lo habían persecutado. En una "pintura" anterior a la Conquista, pintura que pertenecía a la biblioteca de Motecubzoma, está representado el regreso de los hijos de Topiltzin, regreso confundido con la llegada de los primeros Españoles.

Topiltzin hubiera, según el relato de un anciano a Durán, dejado un gran libro escrito en letras, hecho que fortalece el franciscano en su creencia de un antiguo contacto con el mundo judeo-cristiano. Desafortunadamente, Durán no puede ver este libro: había sido quemado por los indígenas seis años antes por dos razones: no sabían leer las letras (las letras no se parecían a sus "pinturas" y tampoco a las letras de los Españoles) y temían que esta propiedad les perjudicara. Todo esto induce el padre Durán a emitir la hipótesis de que se trata quizás del evangelio en hebreo.

Los indígenas, según Durán, "escribían" por medio de "pinturas" y de "efigies" del mismo modo como nosotros lo hacemos con letras. Escribían mucho y en muchos campos 55 . Se consultaba diario a estas "pinturas", sobre todo las del calendario ritual, aún para las tareas más prosaicas. Se jugaba sobre ellas, se echaba suerte: si caía sobre el dios de la vida, uno podía esperarse una larga vida, si...sobre el dios de la muerte...una corta vida ${ }^{56}$. Durán piensa que algunas "pinturas" relativas a la religión ${ }^{57}$ están "cifradas" y compuestas "por unos caracteres ininteligibles". En resumen, las "pinturas" servían de letras con las cuales los escribas anotaban todo $y$, con esmero particular, la historia.

Durán da mucha importancia a las "pinturas" como pruebas de acontecimientos que no fueron relatados por escrito, como por ejemplo, el encadenamiento y la muerte de Motecubzoma (y de sus séquitos) a puñaladas y no a pedrada ${ }^{58}$, hechos que fueron ocultados por los Españoles.

Los autores de las Relaciones Geográficas, empezadas en 1577 bajo el reino de Felipe II se refieren continuamente a las "pinturas" y acompañan muy a menudo sus escritos de mapas que no son sino "pinturas" que mandan hacer a los letrados indígenas. 
En la Relación de Quiotepeque (Mixteca) redactada en $1579^{59}$, un franciscano anónimo quema un libro religioso junto con otros ídolos, porque no lo puede leer. Este libro, venerado por los indígenas, había sido traído por un hombre blanco - Mesías ? - en tiempos muy remotos.

En la Relación de Texcoco fechada en 1582, Juan Bautista Pomar deja entender que los indios no tenían un sistema de escritura y que las "pinturas no son muy capaces para retener en ellas la memoria de las cosas que se pin$\tan . . " 60$.

En la Relación de Tlaxcala redactada entre 1584 y $1585^{\circ 1}$, Diego Muñoz Camargo relata que las "pinturas" y "caracteres" que figuran en los calendarios son "concertadas y justas" y que se pueden leer... El cómputo del tiempo que aparece en ellas sería heredado de los tiempos antiguos, cuando se ejercía la influencia judeo-cristiana.

El padre Juan de Tovar es encargado en 1587 por el virrey Enriquez ${ }^{62}$ del estudio de las "antigüedades" de los indios con el propósito de hacer un resumen que mandar al rey. Para ayudarlo en esta tarea, el virrey encarga unos letrados de México, Texcoco y Tula de traerle"unas "pinturas" sobre la historia de estos señoríos. Tovar menciona en una carta que sin la ayuda de estos letrados, no hubiera podido entender los "caracteres y jeroglíficos" que constituyen los manuscritos.

El padre Juan de Acosta, cuya obra esta publicada en 1590 , describe lo que ahora llamaríamos ideogramas que el designa con el nombre de "jeroglificos" 63 "... porque tenían sus figuras y jeroglificas con que pintaban las cosas en esta forma, que las cosas que tenian figuras las ponian con sus propias imágenes, y para las cosas que no habia imagen propia, tenían otros caracteres significativos de aquello, y con este modo figuraban cuanto querian". Sin embargo sus "figuras" y "caracteres", declara él, tienen un límite: no eran suficientes como nuestra escritura; en sus manuscritos no aparece sino lo "sustancial" de los conceptos. Acosta indica el sentido de la lectura de algunos documentos: "comenzando de abajo iban subiendo..." Pensamos que se debe referir a la Matricula de Tributos. Fr. Gregorio García ${ }^{64}$ repite lo que dice Acosta.

Para Fr. Jerónimo de Mendieta cuya Historia esta terminada en $1597^{\text {6s }}$ los indígenas no tenían escritura. Sin embargo se ayudaban por medio de "pinturas" y de "caracteres" que usaban como letras y servían sobre todo "...para hacer memoria..". Mendieta cuenta como los indios se van a confesar llevando las "pinturas" de sus pecados, como reconstituyeron el Pater Noster en imágenes (dibujan las imágenes de las palabras que fonéticamente más se parecen a las palabras castellanas) y como Jacobo de Testera predicaba con la ayuda de un intérprete indígena que cargaba con él "en un lienzo 
pintado todos los misterios de nuestra santa fe católica". Aurore MonodBecquelin y Joaquín Galarza estudiaron detenidamente a las imágenes de la Doctrina Christiana.

De un franciscano, Mendieta tiene la noticia ${ }^{66}$ de que unas "pinturas" antiguas hechas sobre cuero procedentes de la costa del Pacífico, conservadas en el convento dominico de Nexapa (Oaxaca) representan "tres o cuatro cosas tocante a nuestra fe" que eran según él: la madre de la virgen, la virgen (prototipo de Guadalupe) y dos hermanas de ella "tenidas por santas", vestidas en el modo indígena. Estaban también representadas la crucifixión y la resurrección. La descripción del Cristo crucificado recuerda extrañamente al sacrificio del Tlacacaliliztli .

Le llega a Mendieta de un dominico ${ }^{67}$ que había pasado tiempo con los Otomis, la noticia de que ellos, por varias generaciones, habían tenido un libro que se pasaban de padre a hijo y era objeto de veneración: a las "paginas" no se les daba vuelta con la mano sino con una varita especial para no amancillarlo. El libro contenía una doctrina semejante a la doctrina cristiana, se hablaba del diluvio,... de la anunciación y aparecía pintada la imagen del Cristo crucificado. Desafortunadamente el libro "se había perdido": al ser enterrado a la llegada de los Españoles por miedo de que ellos lo destruyeran, se había podrido. Como otros religiosos, Mendieta cree a una presencia cristiana antigua en América.

- Fr. Juan de Torquemada termina la Monarquía Indiana en 1613. Ahl explica como los indios a pesar de no tener "letras", usaban "un modo de escritura" hecha de los que ahora llamaríamos ideogramas: "... cada pintura significaba una cosa y a veces sucedía que una sola figura, contenía la mayor parte del caso sucedido o todo." Con estas figuras escribieron los indígenas la historia de su llegada a la tierras del Anáhuac, en los muchos libros que se encontraron en el momento de la Conquista. El franciscano es el único en decir: "...que por los caracteres con que se entendían, pudieron estar pintadas (las leyes) y esta es escritura; que toda aquella pintura, y carácter es letra; que sirve de oficio de letra y por la cual se entienden las cosas por ellas significadas." 68 .

Desafortunadamente según Torquemada, el sistema de escritura tenía varios defectos entre los cuales los más importantes eran: el primero la variabilidad de un área a otra de las figuras lo que impedía un verdadero conocimiento de la historia de los "moradores"; el segundo, el carácter hermético de la "lectura" de las figuras que podían efectuar: "... sólo los rabinos y maestros de ella, los que lo eran, en el arte de pintar..." Este "modo" se parecía al de los Cartagineses ${ }^{69}$, antepasados según él de los indios. Las "letras" de los Cartagineses eran "letras reales de cosas pintadas" como eran las "pinturas" 
en las cuales Eneas leyó la destrucción de Troia, como eran las "figuras" que aparecen pintadas en retablos y como últimamente eran las "letras" que usaban los indios (y que siguen usando en 1613 según el testimonio de Torquemada). La prueba de esta "filiación", es decir del origen cartaginense de los indios se puede encontrar en las "pinturas" que illustran la llegada a las Indias Occidentales y en particular en las tierras del Anahuac desde África ( $y$ la costa de Berberia, 29)...!

El descendiente de los reyes de Texcoco, Fernando de Alva Ixtlilxochitl"7, habla en sus Relaciones, redactadas entre 1600-1640 de "escritura en pinturas y caracteres que son sus letras".

\section{CONCLUSIÓN}

Aunque los letrados españoles de los principios de la época colonial hayan observado que los indios de la Nueva-España sabían tomar nota, leer, conservar y entender las "pinturas" que según algunos de ellos se parecían a jeroglíficos, negaron más o menos rotundamente la existencia de un sistema de escritura. De acuerdo con los criterios del siglo XVI, una escritura nada más puede estar compuesta de letras.

De acuerdo con Juan Batista Pomar, Fr. J. de Mendieta y Fr. B. de Sahagún, el sistema de expresión gráfica de las "pinturas" no sirve sino para memorizar datos.

Fray Toribio de Motolinía, el Padre José de Acosta et Fray Juan de Torquemada son los únicos en usar el término de escritura o de "manera de escribir": las "pinturas" eran utilizadas como si fueran letras, algunas eran ideogramas, había un sentido que seguir para leerlas.

No se les puede reprochar a los Españoles de no haber encontrado en los documentos indígenas un sistema de escritura. En realidad no es sino ahora, en esta segunda mitad del siglo XX que los investigadores y una minoría entre ellos, consideran que los manuscritos indígenas del México Central están compuestos de una escritura que se calificó de pictográfica y cuyo descifre no empezó sino en los años cuarenta con el doctor Alfonso Caso.

Según la definición más moderna de la escritura que fue dada por Aurore Monod-Becquelin y Joaquín Galarza en 1980, al final de su investigación sobre la Doctrina Christiana la escritura es: "un conjunto formado de unidades gráficas, recurrentes, combinables, transcribiendo unidades fonéticas y semánticas de una lengua dada". Entonces, las "pinturas" que los espanoles vieron en los siglos XVI y XVII son escritura. 


\section{NOTAS}

1 Cartas de Relación, 1985, 75.

2 Ibid., 124.

3 Es el Ficus benjamina, de la familia de las moráceas.

4 Cartas de Relación, op. cit., 339.

5 Ibid., 143.

6 Historia Verdadera de la Conquista de la Nueva-España, 1972, 188, 192, 202, 235, 354-55, 419.

7 Relación de Texcoco, 1986, III, 46; Torquemada Fr. Juan de, 1969, I, 75, 253.

8 D'Olwer L. N., 1990, 22.

9 Libro de oro y tesoro índico, in : Garcla Icazbalceta J.: Nueva Colección de Documentos, III, 1941, 283-285.

10 Durán Fr. D., 1967, II, 27; Alva Ixtlilxochitl F. de, 1975, I, 18, 51, 205, 527; Historia General de las Cosas de la Nueva-España, 1969, III, 165.

11 Acosta J. de, 1979, 288-290; en junio de 1562 según el padre Garibay 1959, XIII.

12 Relación de Texcoco, op. cit., 46; Alva Ixtlilxochitl F. de, op. cit., I, 205, 527.

13 Durán, Fr. D, op. cit., I, 13; Relación de Texcoco, op. cit., 46.

14 Proceso Criminal del Santo Oficio de la Inquisición contra Don Carlos, Indio Principal de Texcoco, 1968.

15 Relación de Texcoco, ibid., op. cit., Proceso Criminal, ibid., op. cit.

16 Durán Fr. D., op. cit., I, 13; II, 237; Torquemada Fr. J. de, op. cit., I, 75.

17 Relación de Quiotepeque, 1984, I, 236.

18 Alva Ixtlilxochitl, F. de, op. cit., I, 270.

19 Durán Fr. D. , op. cit.,I, 226.

20 Mendieta Fr. J. de, 1971, 77, 81.

21 Se trata de los reinos de Texcoco, Tlaxcala, Huexotzingo, Cholula, Tepeaca, Tlalmanalco...

22 Motolinia Fr. T. de, 1969, 198, 199.

23 López de Gómara F., 1979, 312.

24 Historia Verdadera de la Conquista de la Nueva Esparia, op. cit., 188.

25 Motolinia Fr. T. de, op. cit., 111; Mendieta Fr. J. de, op. cit., 249.

26 Durán Fr. D., op. cit., II, 514-515.

27 Motolinia Fr. T. de, op. cit., 198.

28 Durán Fr. D., op. cit., II, 514.

29 Alva Ixtlilxochitl F. de, op. cit., I, 381, 527.

30 Mendieta Fr. J. de, op. cit., I, 191; Motolinfa Fr. T. de, op. cit., 306

31 Motolinfa Fr. T. de, op. cit., 126.

32 Torquemada Fr. J. de, op. cit., I, 31.

33 Durán Fr. D., op. cit., I, 191. Relación de Texcoco, op. cit., III, 86.

34 Landa Fr. D. de, 1959, 15.

35 Alva Ixtlilxochitl F. de, op. cit., I, 527-528.

36 Relación de Texcoco, op. cit., 45-47; Alva Ixtlilxochitl F. de, op. cit., I, 525. 
37 Acosta, J. de, 1979, 284.

38 García Fr. G., 1981,

39 Acosta, J. de, op. cit., 289; García Fr. G, op. cit., 44.

40 Durán Fr. D, op. cit., II, 232; Mendieta Fr. J. de, 1971, 98.

41 Mendieta Fr. J. de, op. cit., 135.

42 Durán Fr. D., op. cit., II, 514.

43 García Fr. G., op. cit., 44.

44 Durán Fr. D., op. cit., I, 13.

45 Torquemada Fr. J. de, op. cit., I, 28-30.

46 Mufioz Camargo D. , 1984, 107.

47 Mendieta Fr. J. de , op.cit., 539; Relación de Quiotepeque, op. cit., 236.

48 Mendieta Fr. J. de, op. cit., 538.

49 Durán Fr. D., op. cit., I, 13.

50 Mendieta Fr. J. de, op. cit., 538.

51 Historia de los Indios de la Nueva-España, 1969, 2, 151; Memoriales, 1967, 111, 312.

52 Historia de la Conquista de México, op. cit., 312

53 Historia General de las Cosas de Nueva-España, 1969, III, 165.

54 Durán Fr. D., op. cit., II, 14-15; I, 9-13; I, 15.

55 Ibid., I, 226-228.

56 Ibid.

57 Las que tratan por ejemplo de la vida ejemplar de Topiltzin (1967, I, 13).

58 Durán Fr. D., op. cit., II, 556.

59 Relación de Quiotepeque, op. cit., 236.

60 Relación de Texcoco, op. cit. 86.

61 Relacion de Tlaxcala, op. cit., 107.

62 The Tovar calendar, 1951,77-78.

63 Acosta J. de, op. cit., 289, 292.

64 Garcla G. Fr., op. cit., 289.

65 Mendieta Fr. J. de, op. cit., 143, 246, 537.

66 Mendieta, Fr. J. de, op. cit., 537-538.

67 Ibid., 538-539.

68 Torquemada, Fr. J.de, op. cit., II, 314.

69 Ibid., I, 28-31. Los indios de la Nueva-España serían los hijos de Cham, tercer hijo de Noe. Torquemada se basa en las hipótesis d'Alexo Venegas fundadas ellas sobre las de Aristóteles.

70 Alva Ixtlilxochitl, F. de, op. cit., II, 314. 
RECONOCIMIENTO O NEGACIÓN POR LOS ESPAÑoles DEL SIGLO XVI OE UN SISTEMA de ESCRITURA...

\section{B I B L I O G R A FI A}

ACOSTA, PADRE JOSE DE. 1979 - Historia Natural y Moral de las Indias en que se tratan de las cosas notables del cielo, elementos, metales, plantas y animales dellas y los ritos y ceremonias, leyes y gobierno de los indios . 444 p., FCE, Mexico.

ALVA IXTLILXOCHITL, FERNANDO DE. 1975 - Historia Chichimeca (copie n 208, BNP). In: Obras Historicas de Fernando de Alva Ixtlilxochitl . - 566 p., UNAM - IIH - notas de o' Gorman Edmundo, México.

CORTES, HERNÁN. 1985 - Cartas de Relación . - 437 p., Historia 16 - notas de Hernández Sánchez Mario, Madrid.

DIAZ DEL CASTILLO, BERNAL. 1968 - Historia Verdadera de la Conquista de la Nueva España . 2 vol., Porrúa, introd. de Ramírez Cabanas Joaquín, México.

DURAN, FRAY DIEGO. 1967 - Historia de las Indias de Nueva España e Islas de Tierra Firme . 2 vol., Porrúa, México.

GALARZA, JOAQUÍN ET AURORE MONOD-BECQUELIN. 1980 - Doctrina Christiana, Le Pater Noster, 134 p., Société d'Ethnographie, Recherches Américaines 2, Paris.

GARCIA, FRAY GREGORIO. 1981 - Origen de los Indios del Nuevo Mundo . 419 p., FCE. notas de Franklin Pease, México.

GARCIA ICAZBALCETA, JOAQUIN. 1941 - Nueva Colección de Documentos para la Historia de México, 3 vol., Mexico.

KUBLER, GEORGE A ET CHARLES DIBBLE. 1951 - The Tovar Calendar, Memoirs of the Connecticut Academy of Art and Sciences, 9, New Haven.

LANDA, FR. DIEGO DE. 1959 - Relación de las cosas de Yucatdn, Porrúa, introd. de Garibay Angel María, 242 p., México.

LOPEZ DE GOMARA, FRANCISCO. 1979 - Historia de la Conquista de Mexico (lera ed. 1552, Agustín Millan, Saragosse), Biblioteca Ayacucho, 402 p., Caracas.

MENDIETA, FR. JERÓNIMO DE. 1971 - Historia Eclesidstica Indiana, Porrúa, introd. de Garcla Icazbalceta Joaquín, 790 p., México.

MOTOLINIA, FR. TORIBIO DE. 1967 - Memoriales, Avifa Levy Edmundo, 364 p., Guadalajarra. - 1969 - Historia de los Indios de la Nueva España, Porrúa, introd. de o' Gorman Edmundo, 256 p., México.

OLWER, LUIS NICOLAU D'. 1990 - Fray Bernardino de Sabaguin, Departamento del Distrito Federal, 229 p., Mexico.

POMAR, JUAN BAUTISTA. 1986 - Relación de Texcoco, in:

- Relaciones Geográficas del Siglo XVI: México. UNAM - IIA, edic. Acunia René, vol. III, pp. 13113, México.

- Proceso Criminal del Santo Oficio de la Inquisición contra Don Carlos, Indio Principal de Texcoco. 1968 - Avifa Levy Edmundo, 89 p., Guadalajarra.

RELACION DE QUIOTEPEQUE. 1984 - in: Relaciones Geogrdficas del Siglo XVI: Antequera, UNAM - ILA, vol. I, pp. 235-238, México.

SAHAGÚN, FR. BERNARDINO DE. 1969 - Historia general de las Cosas de Nueva España, Porrúa, introd. y notas de Garibay Angel María, 4 vol., México.

TORQUEMADA, FR JUAN DE. 1969 - Monarquia Indiana, Porrúa, 3 vol., introd. y notas de León Portilla Miguel, México. 